\title{
Enzyme variability in large-lake Daphnia populations
}

\author{
Mona A. Mort* and \\ Hans Georg Wolf
}

\author{
Max-Planck-Institut für Limnologie, Abteilung \\ ökophysiologie, Postfach 165, D-2320 Plön, Federal \\ Republic of Germany.
}

\begin{abstract}
Allozyme studies of two primarily parthenogenetic, large-lake Daphnia species, D. galeata mendotae and D. cucullata, revealed high clonal diversity and levels of enzyme polymorphism similar to those found in other groups of organisms. Temporal analyses showed moderate stability of genotypes. Hardy-Weinberg deviations were detected on some dates in D. cucullata, most often resulting from homozygote excesses. Thus, these populations show higher genetic diversity and greater temporal stability than expected on the basis of previous studies of permanent pond populations of other cladocerans.
\end{abstract}

\section{INTRODUCTION}

Cyclical parthenogens exhibit both asexual and sexual reproduction; they therefore allow the assessment of the genetic consequences and evolutionary ramifications of switching reproductive modes. Daphnia populations are of interest in this respect because of their capacity for cyclical parthenogenesis and because of the link between ecological factors and the timing and intensity of sexual reproduction. The association between the characteristics of the physical environment, the relative incidence of sexual reproduction, and the genetic structure of the population, has been previously emphasized (Hebert, 1980). Most Daphnia populations inhabiting temporary ponds form sexual resting eggs which persist through dry periods until the proper environment reappears (some forms parthenogenetically produce resting eggs, see Hutchinson 1967, Hebert and Crease 1980). In populations inhabiting permanent water bodies, the relative constancy of the environment appears to decrease the frequency of resting egg production. In some large-lake populations, resting eggs have not been found (Hutchinson, 1967: 596).

\footnotetext{
* Present address: Department of Zoology, Biological Sciences Centre, The University of Alberta, Edmonton, Alberta, Canada T6G 2E9.
}

Until recently, genetic studies of cyclically parthenogenetic Daphnia populations were confined to the pond species D. magna (Hebert, 1974a-d; Hebert and Ward, 1976; Young, $1979 a, b)$, D. pulex (Berger and Sutherland, 1978; Lynch, $1983 ; 1984 a, b)$, most populations of which are believed by Hebert (1983) to consist of obligately parthenogenetic individuals, and $D$. carinata (Hebert and Moran, 1980). In general, these studies have shown that permanent pond populations, when compared to temporary pond populations, tend to exhibit large fluctuations in genotypic frequencies, pronounced Hardy-Weinberg deviations, and low clonal diversity. The results suggest a relationship between the regularity of resting egg production and the genetic structure of pond populations.

Partly because of methodological problems caused by the small size of lake Daphnia, there are relatively few existing data on their population genetics (Mort and Jacobs, 1981; Jacobs, 1982; Mort, 1983; Wolf, 1984). Large-lake species are important not only because of their low frequency of sexual reproduction, but also because they often undergo cycles of phenotypic change. It is of interest to know the genetic structure of populations which exhibit high amounts of phenotypic variability. The present study uses allozyme data from two large-lake Daphnia populations to illustrate that both genotypic diversity and temporal stability of 
genotype frequencies are higher than expected on the basis of previous studies of pond species.

\section{MATERIALS AND METHODS}

\section{Study sites and sampling}

D. galeata mendotae were collected from the deepest area $(13.1 \mathrm{~m})$ of the steep-shored, $2.05 \mathrm{~km}^{2}$ Lake Morey (Vermont, U.S.A.), by oblique tows with a $73 \mu \mathrm{m}$ mesh plankton net. Daphnia were transported to the laboratory within one hour of collection, kept alive in an incubator at lake temperature, and sorted for electrophoresis within 24 hours. Reproductive analysis of the population from October 1978 to December 1981 detected, at various times, parthenogenetic females, sexual females, and males (Mort, 1983). For electrophoretic analyses, only parthenogenetic females were used; the other reproductive classes, when present, were too rare in the live samples to provide sufficient sample sizes for analysis.

To investigate the clonal structure of the $D$. galeata mendotae population, clones were established from stem females obtained from field collections made during August 1981 through May 1982. Clones were cultured in filtered lake-water at $20^{\circ} \mathrm{C}$ under continuous light and fed Cryptomonas. On each of four occasions, 12 to 89 clones were isolated. Low survivorship of clones was encountered, and was at least in part due to mortality resulting from animals caught on the surface film of the medium.

D. cucullata were collected from a $12 \mathrm{~m}$ deep station in the $0.82 \mathrm{~km}^{2}$ Schöhsee (Plön, Holstein, F.R.G.; maximum lake depth $=30 \mathrm{~m}$; mean depth $=13 \mathrm{~m}$ ), by oblique tows with a $250 \mu \mathrm{m}$ mesh plankton net. Daphnia were immediately transported to the laboratory and sorted for electrophoresis within 24 hours of collection. Although this population occasionally contains sexual females and males, only parthenogenetic females were used for electrophoresis. Clonal structure of the population was determined directly from field-caught individuals, by slicing starch gels to assay for multiple enzyme phenotypes per individual.

\section{ELECTROPHORESIS}

\section{Daphnia galeata mendotae}

Electrophoresis was carried out on 7 per cent polyacrylamide vertical slab gels (Aardvark Instru- ments) using methods modified from Manning et al., (1978). The gel consisted of $200 \mathrm{ml} \mathrm{0 \cdot 1} \mathrm{M} \mathrm{Tris-}$ borate buffer $(p \mathrm{H} 8.9,12.114 \mathrm{~g}$ Tris, and $0.25 \mathrm{~g}$ boric acid per litre water), $13.97 \mathrm{~g}$ Cyanogum (E-C Apparatus), $0.33 \mathrm{ml}$ TEMED, and $1.66 \mathrm{ml} 10$ per cent ammonium persulphate. Individual adult females were homogenised in an Adamcewicz microhomogeniser in which $15 \mu$ l of a tris-borate $(p \mathrm{H} \mathrm{8.9)}+$ bromophenol blue +10 per cent sucrose solution had been placed. The electrophoretic separation was carried out at 350 volts for at least $2 \cdot 5$ hours per application of homogenate. The gel slabs were then removed from the apparatus and incubated in the dark in stains modified from Shaw and Prasad (1970). Stain recipes are given in Mort (1983). The following enzymes were successfully stained in single individuals: glutamate oxaloacetate transaminase (GOT), phosphoglucomutase $(\mathrm{PGM})$, alkaline phosphatase (ALK), alphaesterase (EST), beta-esterase ( $\beta$-EST), acid phosphatase (ACP), phosphoglucose isomerase (PGI), malic dehydrogenase (MDH), and xanthine dehydrogenase $(\mathrm{XDH})$.

\section{Daphnia cucullata}

Electrophoresis was carried out on 11 per cent horizontal starch gels (DESAGA, Heidelberg) using methods modified from Wolf (1982). The gel consisted of $80 \mathrm{ml} 0.14 \mathrm{M}$ Tris-citrate buffer $(p \mathrm{H} 8.5,16.4 \mathrm{~g}$ Tris, $0.4 \mathrm{~g}$ EDTA, and $4 \mathrm{~g}$ citric acid per litre water), $1 \cdot 12$ litres water, and $130 \mathrm{~g}$ starch (SIGMA). Individual adult females were homogenised in Microtiter plates with $20 \mu \mathrm{l}$ Triscitrate $(0.01 \mathrm{M})$ and bromophenol blue. The homogenate was soaked into filter paper wicks (Whatman No.3) and loaded onto the gels. The electrophoretic separation was carried out at $10 \mathrm{~mA}$ for 0.5 hours. The wicks were then removed and the separation was continued for 5.5 hours at $30 \mathrm{~mA}$. The gel slab was separated into three to four slices and incubated in the dark in stains slightly modified from Wolf (1982). The major modification of the protocol is the deletion of Triton from the gel; instead, $50 \mu l$ Triton X$100 / 100 \mathrm{ml}$ stain is added to PGI, PGM, and MDH. PGI and PGM have sufficiently different mobility so that they may be stained on the same slice. The other enzymes stained were: GOT, fumarase (FUM), lactate dehydrogenase (LDH), NADP-dependent malic dehydrogenase (ME), glucose-6-phosphate dehydrogenase (G-6-PDH), and 6-phosphogluconate dehydrogenase (6PGDH). 
RESULTS

\section{Population characteristics}

In both Daphnia populations considered here, reproduction occurs primarily via parthenogenesis. Reproductive analysis of the $D$. galeata mendotae population from October 1978 through December 1981 showed that sexual reproduction, occurring in October through December, was low and varied from year to year. During the 3-year period of analysis, sexual females constituted a maximum of 8 per cent of the population (Mort, 1983). Similarly, in the $D$. cucullata population, sexual reproduction was detected in November and December and reached a maximum of 5 per cent during the 2-year period of 1981 and 1982 (W. Lampert, personal communication).

Cyclical phenotypic change, also known as cyclomorphosis (see Hutchinson, 1967), was exhibited by both populations. Phenotypic changes involved changes in size and shape of the head with associated changes in the length of the tailspine. The phenotypic changes follow the same pattern as water temperature; maximum expression of the characters is in late summer when temperatures are highest. In the $D$. galeata mendotae population, the head length of both juveniles and adults ranged from 8 per cent (winter) to 26 per cent (summer) of the body length, in a pattern which was repeated yearly from 1979 through 1982 (Mort, in preparation). D. cucullata exhibited similar, but more pronounced, phenotypic changes with a head length range of 8 per cent (winter) to 56 per cent (summer) of the body length during 1981 and 1982 (Lampert and Wolf, in preparation).

\section{Enzyme variability}

Of the nine enzyme systems examined in $D$. galeata mendotae, three (PGI, MDH, XDH) were invariant and the remaining six were polymorphic (GOT, PGM, ALK-2, EST, $\beta$-EST, ACP). Of the nine loci examined in $D$. cucullata, five were invariant (ME, FUM, LDH, G-6-PDH, 6-PGDH) and the remaining four (PGM, PGI, MDH, GOT) were polymorphic.

\section{Enzyme phenotypes}

For $D$. galeata mendotae, four polymorphic loci (GOT, PGM, ALK-2, EST-2) were used to investigate the genetic structure of the population. Segregation at these loci could not be confirmed by mating experiments because of unsuccessful attempts to induce mating in the laboratory. Thus, the genetic basis of the enzyme patterns is inferred from laboratory-raised individuals and from previous studies (Hebert and Ward, 1972). GOT, a dimeric enzyme, exhibited two phenotypes, singlebanded and triple-banded, which were identified as SS homozygotes and SF heterozygotes, respectively. PGM, a monomer, exhibited three phenotypes: two single-banded designated FF and SS homozygotes and one double-banded designated an SF heterozygote. The alpha-EST staining procedure yielded two zones of activity, EST-1 and EST-2. EST-1 activity was not found in all individuals and is not further considered. EST-2, a monomer, showed three phenotypes: two single bands designated SS and FF homozygotes and one double band designated an SF heterozygote. Four zones of alkaline phosphatase activity were detected in $D$. galeata mendotae, probably representing enzyme activity at four distinct loci. Only the second zone, ALK-2, was found in all individuals. Three enzyme phenotypes were present at ALK-2: two single-banded patterns designated SS and FF homozygotes and one double-banded pattern designated an SF heterozygote. EST-2 and ALK-2 phenotypes were stable in laboratory clones.

In $D$. cucullata, of the four polymorphic loci identified, two (PGI, PGM) were regularly used to investigate the genetic structure of the population. PGM exhibited three phenotypes: two single bands interpreted to represent SS and FF homozygotes and one double band designated an SF heterozygote. PGI, a dimeric enzyme, is polymorphic for four alleles represented by ten phenotypes: $\mathrm{S}^{-} \mathrm{S}^{-}, \mathrm{SS}, \mathrm{MM}, \mathrm{FF}, \mathrm{S}^{-} \mathrm{S}, \mathrm{S}^{-} \mathrm{M}, \mathrm{S}^{-} \mathrm{F}, \mathrm{SM}, \mathrm{SF}, \mathrm{MF}$. Homozygotes were single-banded; heterozygotes were triple-banded. On a few occasions, MDH activity was high enough that it could be assayed as a third locus in individual Daphnia. MDH, a dimeric enzyme, is polymorphic for three alleles resulting in six phenotypes: SS, MM, FF, SM, SF, MF. MDH homozygotes were single-banded; heterozygotes were triple-banded. GOT could only be assayed in exceptionally large $D$. cucullata, which were present only on a few occasions. Two alleles resulting in three phenotypes (SS, FF, SF) were detected. Homozygotes were single-banded; heterozygotes were triple-banded.

\section{Clonal diversity}

For the D. galeata mendotae population, clonal structure was investigated by electrophoretic analysis of 27 clones established from field collections. Analysis at four loci (GOT, PGM, ALK-2, EST-2; table 1) revealed 14 distinct genotypes. 
Table 1 Clonal groups detected in the Lake Morey $D$. galeata mendotae population; based on laboratory clones originating from field collections

\begin{tabular}{llllll}
\hline \multicolumn{2}{l}{ Genotype } & \multicolumn{4}{l}{} \\
GOT & PGM & ALK-2 & EST-2 & Frequency & $\begin{array}{l}\text { Proportion } \\
\text { of total }\end{array}$ \\
\hline SS & SS & SF & SS & 1 & 0.037 \\
SS & SF & SS & SS & 3 & 0.112 \\
SS & SF & SS & SF & 7 & 0.259 \\
SS & SF & SF & SS & 5 & 0.185 \\
SS & SF & SF & SF & 2 & 0.074 \\
SS & FF & SS & SS & 1 & 0.037 \\
SS & FF & SS & SF & 1 & 0.037 \\
SS & FF & SS & FF & 1 & 0.037 \\
SS & FF & SF & FF & 1 & 0.037 \\
SS & FF & FF & SF & 1 & 0.037 \\
SF & SF & SF & SF & 1 & 0.037 \\
SF & FF & SS & SS & 1 & 0.037 \\
SF & FF & SS & SF & 1 & 0.037 \\
SF & FF & FF & SF & 1 & 0.037 \\
\hline
\end{tabular}

Table 2 Clonal groups detected in the Schöhsee $D$. cucullata population; based on field-caught individuals

\begin{tabular}{|c|c|c|c|}
\hline PGM & PGI & Frequency & $\begin{array}{l}\text { Proportion } \\
\text { total }\end{array}$ \\
\hline SS & $\mathrm{S}^{-} \mathrm{S}^{--}$ & 8 & 0.002 \\
\hline SS & SS & 302 & 0.084 \\
\hline SS & MM & 40 & 0.011 \\
\hline SS & $\mathrm{FF}$ & 3 & 0.001 \\
\hline SS & $\mathrm{S}^{-\mathrm{S}}$ & 124 & 0.035 \\
\hline SS & $\mathrm{S}^{-} \mathrm{M}$ & 18 & 0.005 \\
\hline SS & $\mathrm{S}^{-} \mathrm{F}$ & 4 & 0.001 \\
\hline SS & SM & 151 & 0.042 \\
\hline SS & SF & 30 & 0.008 \\
\hline SS & MF & 6 & $0 \cdot 002$ \\
\hline SF & $\mathrm{S}^{-} \mathrm{S}^{\prime \prime}$ & 18 & $0 \cdot 005$ \\
\hline SF & SS & 693 & 0.194 \\
\hline SF & $\mathbf{M M}$ & 86 & 0.024 \\
\hline SF & $\mathrm{FF}$ & 7 & 0.002 \\
\hline $\mathrm{SF}$ & $\mathrm{S}^{-} \mathrm{S}$ & 273 & 0.076 \\
\hline SF & $\mathrm{S}^{-} \mathrm{M}$ & 60 & 0.017 \\
\hline SF & $\mathrm{S}^{-} \mathrm{F}$ & 22 & 0.006 \\
\hline SF & SM & 270 & 0.075 \\
\hline $\mathrm{SF}$ & SF & 66 & 0.018 \\
\hline SF & MF & 21 & $0 \cdot 006$ \\
\hline $\mathrm{FF}$ & $S \mathrm{~S}$ & 8 & 0.002 \\
\hline FF & SS & 601 & $0 \cdot 168$ \\
\hline FF & MM & 153 & 0.043 \\
\hline $\mathrm{FF}$ & $\mathrm{FF}$ & 4 & 0.001 \\
\hline $\mathrm{FF}$ & $\mathrm{S}^{-} \mathrm{S}$ & 215 & $0 \cdot 060$ \\
\hline $\mathrm{FF}$ & $\mathrm{S}^{-} \mathrm{M}$ & 35 & 0.010 \\
\hline $\mathrm{FF}$ & $\mathrm{S}^{-} \mathrm{F}$ & 11 & 0.003 \\
\hline FF & SM & 247 & 0.069 \\
\hline FF & SF & 92 & 0.026 \\
\hline FF & $\mathrm{MF}$ & 14 & 0.004 \\
\hline
\end{tabular}

Since 54 genotypic combinations are possible and since most genotypes were rare, analysis of a larger number of clones would probably increase the number of genotypes detected. Because analysis at more loci would also be likely to increase the number of genotypes detected, this technique identifies clonal groups wh: 2 can themselves contain a large number of distinct genotypes. Thus, the present analysis suggests that the population contains a large number of distinct genotypes which, because reproduction is primarily parthenogenetic, can be taken as evidence that the population contains a large number of clones.

D. cucullata individuals were routinely characterised at both PGM and PGI. During 1982, all of the 30 possible PGI-PGM genotypes were detected (table 2). Linkage relationships between the loci were determined with an EM (ExpectationMaximization) algorithm (C. Strobeck, personal communication; modified from Cheliak et al., 1983). Significant linkage disequilibrium was detected on one date: 15.6.82 $\left(\chi^{2}=10.78, p<\right.$ $0.05)$. Thus, little association exists between the two loci. In May 1983, D. cucullata individuals were also characterised at $\mathrm{MDH}$. Using the 3-locus genotypes (PGI-PGM-MDH), 60 of the 180 possible combinations were detected. The missing combinations were those containing rare alleles. Thus, as in the $D$. galeata mendotae population, the $D$. cucullata population consists of a large number of coexisting clones.

\section{Temporal analysis of genotypes}

Analysis of the $D$. galeata mendotae population at the GOT locus showed that the genotypes remained fairly constant over time (fig. 1) with no significant temporal heterogeneity $(G=13 \cdot 23, p=$ $0 \cdot 5)$. The GOT-FF genotype was not detected, probably because of its low expected frequency (table 3). Genotypic frequencies showed no significant deviations from Hardy-Weinberg proportions as determined by $\chi^{2}$ tests performed for each sampling date. With an allele near fixation, however, it is difficult to detect such deviations. Calculation of $H=-\left(\sum H_{\exp }-\sum H_{\text {obs }}\right) / \sum H_{\text {exp }}$, where $\sum H_{\text {exp }}$ is the sum of expected heterozygote frequencies and $\sum H_{\mathrm{obs}}$ is the sum of observed heterozygote frequencies, as a measure of deviations from Hardy-Weinberg proportions reveals a permanent heterozygote excess ( $H$ always positive). Also a $\chi^{2}$ test on the pooled data show significant deviations from Hardy-Weinberg proportions $\left(\chi^{2}=15 \cdot 7, p<0 \cdot 001\right)$. 


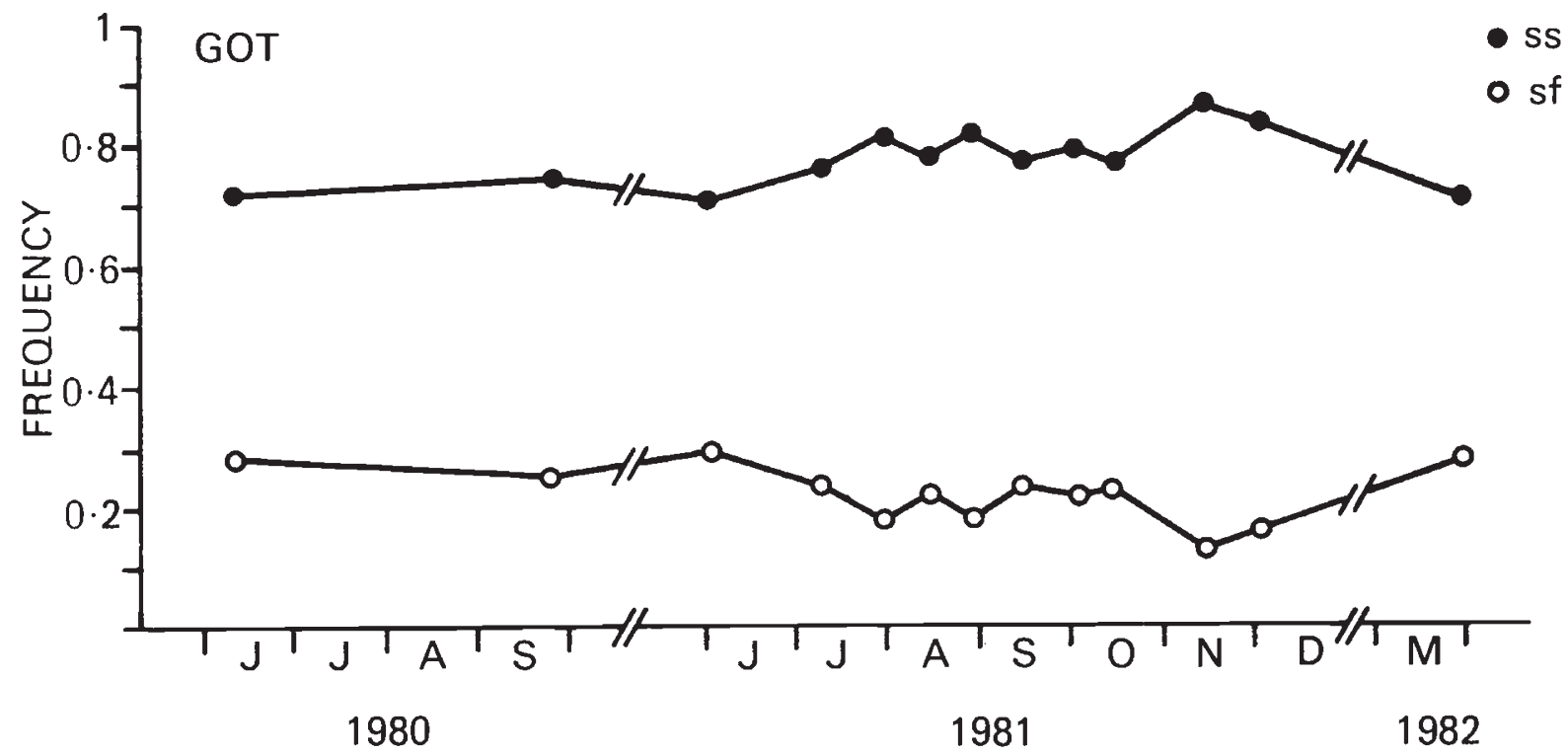

Figure 1 Temporal analysis of GOT genotypes in D. galeata mendotae, Lake Morey.

Because of scoring difficulties, data at the ALK2 locus is limited to 1981. At ALK-2, genotypes remained stable (fig. 2) until the October sample when an increase in both SF and FF genotypes occurred (table 4 ), resulting in significant temporal heterogeneity $(G=36 \cdot 72, p<0 \cdot 001)$. Genotypic frequencies at ALK-2 showed no significant deviations from Hardy-Weinberg proportions which, as at the GOT locus, may have been difficult to detect because of the high frequency of the $S$ allele.

With some exceptions, D. cucullata PGM genotypes remained fairly constant from one sampling date to the next but show significant heterogeneity when the entire 8-month sampling period is considered ( $G=93.19, p<0.001$; fig. 3 ). The FF genotype increased in frequency over this period (table 5). Of the 26 sampling dates, five showed significant deviations from Hardy-Weinberg proportions due to homozygote excesses (table 5). Even when deviations are not statistically significant, the-with two exceptions-constantly negative value of $\mathrm{H}$ suggests homozygote excess.

At PGI, D. cucullata genotypes were moderately stable over time (fig. 4) but also showed

Table 3 GOT genotype and allele frequencies and relative deviations of heterozygote frequencies from Hardy-Weinberg expectations for the D. cucullata population

\begin{tabular}{|c|c|c|c|c|c|c|c|}
\hline \multirow[b]{2}{*}{ Collection date } & \multirow[b]{2}{*}{$\mathrm{N}$} & \multicolumn{3}{|c|}{$\begin{array}{l}\text { Genotype } \\
\text { frequencies }\end{array}$} & \multicolumn{2}{|c|}{$\begin{array}{l}\text { Allele } \\
\text { frequencies }\end{array}$} & \multirow[b]{2}{*}{$\mathrm{H}$} \\
\hline & & SS & SF & $\mathrm{FF}$ & $\mathrm{S}$ & $\mathrm{F}$ & \\
\hline 13.6 .80 & 47 & 0.720 & $0 \cdot 280$ & 0.000 & 0.860 & $0 \cdot 140$ & +0.163 \\
\hline 25.9 .80 & 20 & 0.750 & $0 \cdot 250$ & 0.000 & $0 \cdot 880$ & $0 \cdot 120$ & +0.184 \\
\hline 1.6 .81 & 115 & 0.704 & 0.296 & 0.000 & 0.852 & $0 \cdot 148$ & +0.174 \\
\hline 7.7 .81 & 76 & 0.763 & 0.237 & 0.000 & 0.882 & $0 \cdot 118$ & +0.139 \\
\hline 31.7 .81 & 93 & 0.817 & $0 \cdot 183$ & 0.000 & 0.909 & 0.091 & +0.106 \\
\hline 14.8 .81 & 114 & 0.781 & 0.219 & 0.000 & 0.891 & $0 \cdot 109$ & +0.127 \\
\hline 28.8 .81 & 109 & 0.817 & $0 \cdot 183$ & 0.000 & 0.909 & 0.091 & +0.106 \\
\hline 14.9 .81 & 107 & 0.766 & $0 \cdot 234$ & 0.000 & 0.883 & $0 \cdot 117$ & +0.133 \\
\hline 1.10 .81 & 29 & 0.793 & 0.207 & 0.000 & 0.897 & $0 \cdot 103$ & $+0 \cdot 120$ \\
\hline 15.10 .81 & 75 & 0.773 & 0.227 & 0.000 & 0.886 & $0 \cdot 114$ & +0.124 \\
\hline 13.11 .81 & 102 & 0.873 & 0.127 & 0.000 & 0.937 & 0.063 & +0.076 \\
\hline 1.12 .82 & 128 & 0.844 & $0 \cdot 156$ & 0.000 & 0.922 & 0.078 & +0.085 \\
\hline 27.5 .82 & 66 & 0.712 & $0 \cdot 288$ & 0.000 & 0.856 & 0.144 & +0.168 \\
\hline
\end{tabular}




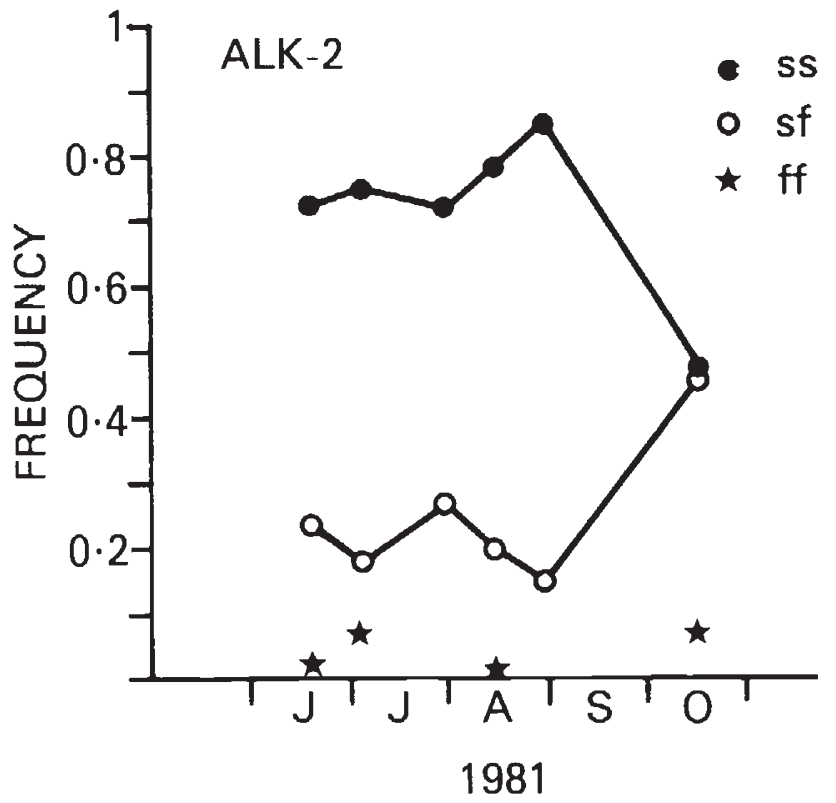

Figure 2 Temporal analysis of ALK-2 genotypes in D. galeata mendotae, Lake Morey. significant temporal heterogeneity $(G=234 \cdot 30$, $p<0.001)$ due to an increase in frequency of the SS genotype (table 6). Deviations from HardyWeinberg proportions were more common at this locus; significant deviations were detected on 15 of the 26 sampling dates (table 6). $\chi^{2}$ tests for Hardy-Weinberg deviations were performed on six classes which included three composite classes containing rare genotypes: 1) $\mathrm{S}^{-} \mathrm{S}^{-}, \mathrm{FF}, \mathrm{S}^{-} \mathrm{F} ; 2$ ) $\left.\mathrm{S}^{-} \mathrm{S}, \mathrm{SF} ; 3\right) \mathrm{S}^{-} \mathrm{M}, \mathrm{MF}$. On dates when significant deviations were detected they were due to an excess of one or both of the common homozygotes (SS, MM) usually accompanied by a smaller excess of at least one of the heterozygotes or heterozygote classes (no heterozygote excesses were present on 24.8 and $19 \cdot 10)$. This small heterozygote excess was not sufficient to change the overall picture of homozygote excess as shown by a negative value of $\mathrm{H}$. However, on one occasion (11.5) there were significant deviations from Hardy-Weinberg proportions due to heterozygote excess. In general, D. cucullata showed a tendency towards homozygote excesses at both loci (value of $\mathrm{H}$ negative).

Table 4 ALK-2 genotype and allele frequencies and relative deviations of heterozygote frequencies from $\mathrm{Hardy}-\mathrm{Weinberg}$ expectations for the $D$. galeata mendotae population

\begin{tabular}{|c|c|c|c|c|c|c|c|}
\hline \multirow[b]{2}{*}{ Collection date } & \multirow[b]{2}{*}{$N$} & \multicolumn{3}{|c|}{$\begin{array}{l}\text { Genotype } \\
\text { frequencies }\end{array}$} & \multicolumn{2}{|c|}{$\begin{array}{l}\text { Allele } \\
\text { frequencies }\end{array}$} & \multirow[b]{2}{*}{$\mathrm{H}$} \\
\hline & & SS & SF & $\mathrm{FF}$ & $S$ & $\mathrm{~F}$ & \\
\hline 19.6 .81 & 62 & 0.726 & $0 \cdot 242$ & 0.032 & 0.847 & $0 \cdot 153$ & -0.066 \\
\hline 3.7 .82 & 16 & 0.750 & $0 \cdot 188$ & 0.062 & 0.844 & $0 \cdot 156$ & $-0 \cdot 286$ \\
\hline 31.7 .81 & 87 & 0.724 & 0.276 & 0.000 & 0.862 & 0.138 & $+0 \cdot 160$ \\
\hline $14 \cdot 8.81$ & 85 & 0.788 & 0.200 & 0.012 & 0.888 & $0 \cdot 112$ & +0.005 \\
\hline 28.8 .81 & 95 & $0 \cdot 853$ & 0.147 & 0.000 & 0.927 & 0.073 & +0.086 \\
\hline 15.10 .81 & 53 & 0.453 & 0.472 & 0.075 & 0.689 & 0.311 & +0.101 \\
\hline
\end{tabular}

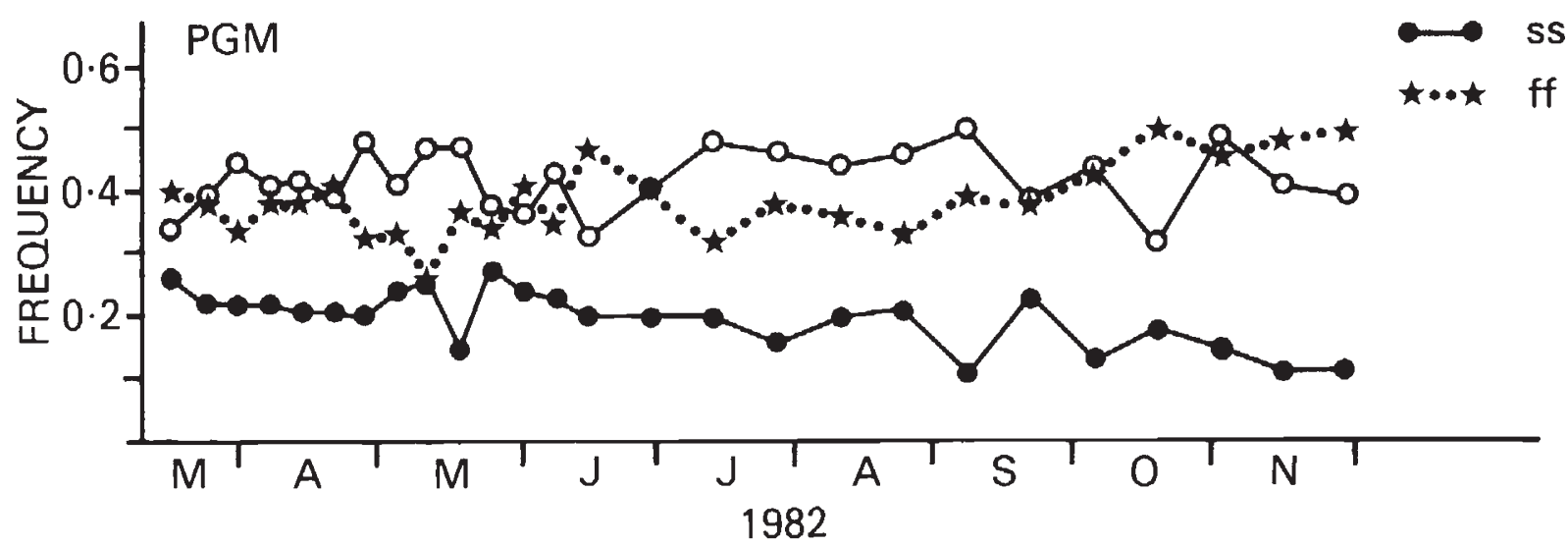

Figure 3 Temporal analysis of PGM genotypes in D. cucullata, Schöhsee. 
Table 5 PGM genotype and allele frequencies and relative deviations of heterozygote frequencies from Hardy-Weinberg expectations for the D. cucullata population

\begin{tabular}{|c|c|c|c|c|c|c|c|}
\hline \multirow[b]{2}{*}{ Collection date } & \multirow[b]{2}{*}{$\mathrm{N}$} & \multicolumn{3}{|c|}{ Genotype frequencies } & \multicolumn{2}{|c|}{ Allele frequencies } & \multirow[b]{2}{*}{$\mathrm{H}$} \\
\hline & & SS & SF & $\mathrm{FF}$ & $\mathrm{S}$ & $F$ & \\
\hline 16.3 .82 & $158^{\dagger}$ & $0 \cdot 259$ & 0.342 & $0 \cdot 399$ & 0.430 & 0.570 & $-0 \cdot 302$ \\
\hline 23.3 .82 & $95^{*}$ & $0 \cdot 221$ & $0 \cdot 368$ & 0.411 & $0 \cdot 405$ & 0.595 & $-0 \cdot 236$ \\
\hline 30.3 .82 & 95 & $0 \cdot 221$ & 0.453 & $0 \cdot 326$ & 0.447 & 0.553 & -0.084 \\
\hline 6.4 .82 & 96 & $0 \cdot 219$ & 0.406 & $0 \cdot 375$ & 0.422 & 0.578 & $-0 \cdot 168$ \\
\hline 13.4 .82 & 72 & $0 \cdot 208$ & 0.417 & 0.375 & 0.417 & 0.583 & $-0 \cdot 142$ \\
\hline 20.4 .82 & 96 & $0 \cdot 208$ & 0.385 & 0.407 & 0.401 & 0.599 & $-0 \cdot 199$ \\
\hline 26.4 .82 & 131 & $0 \cdot 199$ & 0.480 & 0.321 & 0.439 & $0 \cdot 561$ & $-0 \cdot 025$ \\
\hline 4.5 .82 & 87 & $0 \cdot 241$ & 0.414 & $0 \cdot 345$ & $0 \cdot 448$ & 0.552 & $-0 \cdot 163$ \\
\hline 11.5 .82 & 87 & $0 \cdot 264$ & 0.472 & $0 \cdot 264$ & 0.500 & 0.500 & -0.056 \\
\hline 17.5 .82 & 97 & $0 \cdot 155$ & 0.474 & 0.371 & $0 \cdot 392$ & $0 \cdot 608$ & $-0 \cdot 006$ \\
\hline 25.5 .82 & 156 & $0 \cdot 276$ & $0 \cdot 385$ & $0 \cdot 339$ & 0.468 & 0.532 & $-0 \cdot 227$ \\
\hline 1.6 .82 & 135 & $0 \cdot 237$ & 0.356 & 0.407 & 0.415 & 0.585 & -0.267 \\
\hline 8.6 .82 & 93 & 0.226 & 0.430 & $0 \cdot 344$ & 0.441 & 0.559 & $-0 \cdot 128$ \\
\hline 15.6 .82 & $97^{*}$ & $0 \cdot 196$ & $0 \cdot 330$ & 0.474 & $0 \cdot 361$ & 0.639 & -0.285 \\
\hline 29.6 .82 & $188^{*}$ & $0 \cdot 197$ & 0.399 & 0.404 & $0 \cdot 396$ & 0.604 & $-0 \cdot 166$ \\
\hline 13.7 .82 & 191 & $0 \cdot 199$ & 0.476 & $0 \cdot 325$ & 0.437 & 0.563 & -0.033 \\
\hline 27.7 .82 & 186 & $0 \cdot 156$ & 0.462 & $0 \cdot 382$ & 0.387 & 0.613 & -0.026 \\
\hline 10.8 .82 & 187 & $0 \cdot 198$ & 0.438 & $0 \cdot 364$ & 0.417 & 0.583 & -0.099 \\
\hline 24.8 .82 & 188 & $0 \cdot 213$ & 0.457 & 0.330 & 0.442 & 0.558 & -0.074 \\
\hline 7.9 .82 & 185 & $0 \cdot 108$ & 0.497 & 0.395 & 0.357 & 0.643 & +0.083 \\
\hline 20.9 .82 & 179 & $0 \cdot 229$ & $0 \cdot 391$ & $0 \cdot 380$ & 0.425 & 0.575 & $-0 \cdot 200$ \\
\hline 5.10 .82 & 187 & 0.134 & 0.438 & 0.428 & 0.353 & 0.647 & -0.041 \\
\hline 19.10 .82 & $100^{*}$ & $0 \cdot 180$ & 0.320 & 0.500 & $0 \cdot 340$ & 0.660 & $-0 \cdot 287$ \\
\hline 2.11 .82 & 180 & $0 \cdot 150$ & 0.494 & $0 \cdot 356$ & $0 \cdot 397$ & $0 \cdot 603$ & +0.032 \\
\hline 16.11 .82 & 148 & $0 \cdot 108$ & 0.412 & 0.480 & $0 \cdot 314$ & 0.686 & -0.044 \\
\hline 29.11 .82 & 169 & $0 \cdot 112$ & $0 \cdot 391$ & 0.497 & $0 \cdot 308$ & 0.692 & -0.083 \\
\hline
\end{tabular}

$* P<0.05$.

$\dagger p<0.01 ; \chi^{2}$ test for Hardy-Weinberg deviations.

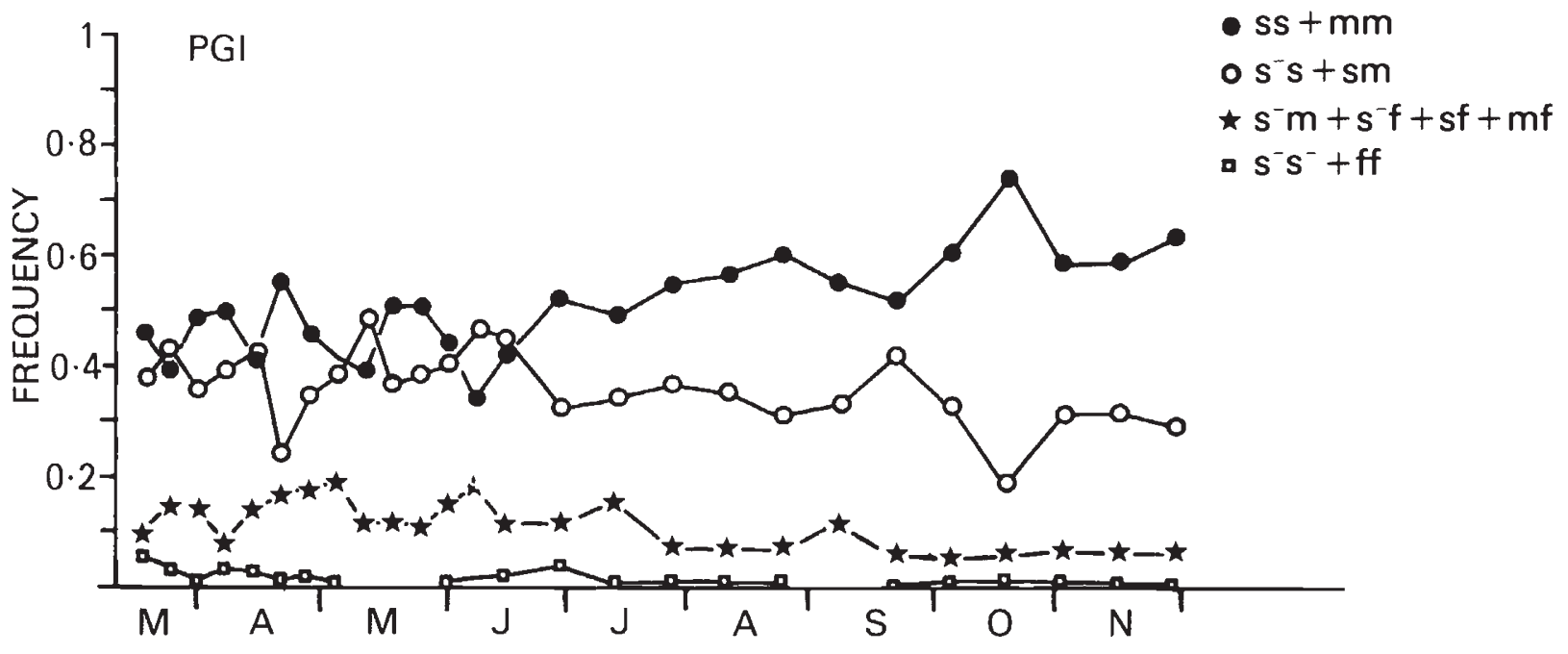

1982

Figure 4 Temporal analysis of PGI genotypes in D. cucullata, Schöhsee. 
Table 6 PGI genotype and allele frequencies and relative deviations of heterozygote frequencies from Hardy-Weinberg expectations for the $D$. cucullata population

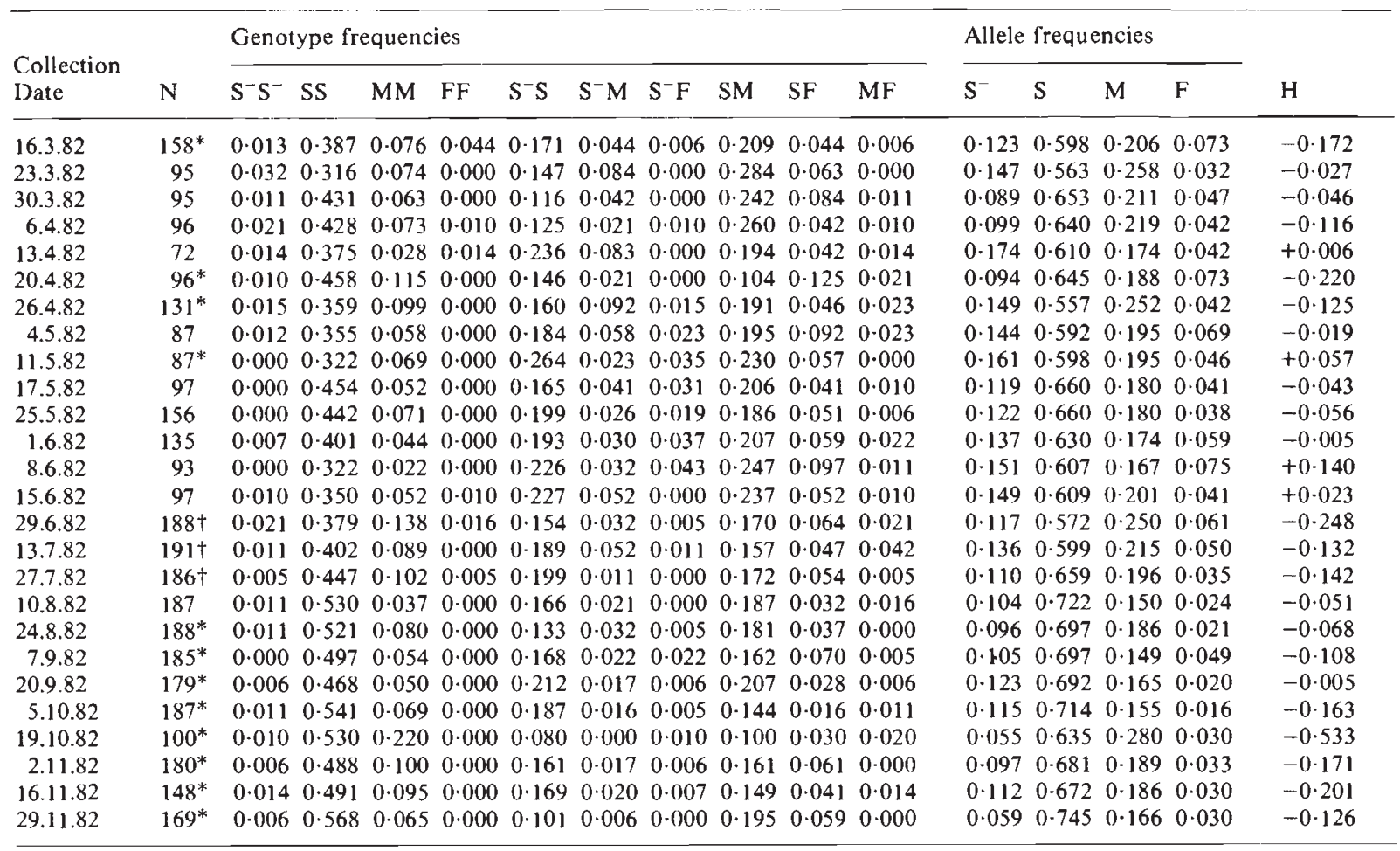

$* p<0 \cdot 05$.

$+p<0 \cdot 01 ; \chi^{2}$ tests for Hardy-Weinberg.

\section{DISCUSSION}

The level of enzyme variability in both $D$. galeata mendotae (66 per cent, based on nine loci) and $D$. cucullata (44 per cent, based on nine loci) is higher than the 11 per cent polymorphism reported by Hebert (1980) for D. magna (based on 15 loci) and $D$. carinata (based on 17 loci, Hebert and Moran, 1980). Since the present estimates of polymorphism are based on fewer loci, it can be argued that the addition of more loci would decrease the estimates. If six additional loci had been examined and found to be monomorphic, the levels of polymorphism would remain high at 40 per cent for $D$. galeata mendotae and 26 per cent for $D$. cucullata. In addition, more recent studies on $D$. pulex report 47 per cent polymorphism (based on 17 loci, Berger and Sutherland, 1978) and 67 per cent polymorphism (based on 15 loci, Lynch 1984a). On the basis of the low levels of polymorphism and the differences in the clonal composition of different populations of $D$. magna and $D$. carinata Hebert (1980) suggested that Daphnia populations were prone to founder effects followed by inbreeding because of the presence of only a small part of the genetic variability of the species in any single population. This conclusion does not seem to be extendable to populations of other Daphnia species, which exhibit levels of polymorphism similar to the 30 per cent to 50 per cent detected in other organisms (Lewontin, 1974). Although we cannot estimate the proportion of the total species variability present in the two populations examined, studies of several large-lake populations of $D$. galeata give little indication of differentiation between populations (Mort and Wolf, in preparation).

Both the $D$. galeata mendotae and $D$. cucullata populations consist of a large number of multilocus genotypes. In $D$. galeata mendotae, 50 per cent of the possible number of 4-locus genotypes were detected; a larger sample size would very likely increase this proportion. In $D$. cucullata, all of the 2-locus (PGI-PGM) combinations were found. Because reproduction is primarily parthenogenetic, these genotypes can be taken to represent 
distinct clonal groups which themselves contain a large number of clones. Thus, the clonal diversity detected in the present study approaches that which has been detected in temporary populations of other Daphnia where the entire population undergoes sexual reproduction (Young, 1979b; Lynch, 1984a). Hebert (1984) and Lynch (1983; $1984 a$ ) have suggested that clonal diversity in the primarily parthenogenetic large-lake populations should be low due to the erosion of genotypic diversity via long-term selection. If long-term erosion of clonal diversity is occurring in the populations considered here, then it is slight, and the low amount of sexual reproduction is apparently sufficient to re-establish genotypic diversity. Genetic diversity could also be augmented by hatching of sexual resting eggs produced during previous seasons. Resting eggs deposited in the lake sediments can persist for several years before hatching (Herzig, 1984). The resting eggs may provide a reservoir from which genetic diversity could be replenished, especially after periods of harsh selection or population bottle-necks.

In $D$. galeata mendotae, temporal stability of genotypes was observed at the GOT locus but not at the ALK-2 locus. The large changes at the ALK-2 locus in the October sample coincided with the onset of sexual reproduction. Since sexual females were not used for electrophoresis, the changes in genotypic frequencies may reflect differential expression of sexual reproduction among genotypes, as has been noted in $D$. pulex (Lynch, 1983), although the changes are too large to be explained only by this phenomenon. In the $D$. cucullata population, significant temporal heterogeneity was observed at both PGM and PGI. In both cases, the temporal heterogeneity was produced by a rise in frequency of a common homozygote, suggesting a shift in the genetic structure of the population.

Thus, significant temporal heterogeneity of genotypes was observed in both the $D$. galeata mendotae and the $D$. cucullata populations. The temporal fluctuations, however, are not as pronounced as those reported by Hebert and Ward (1976) for permanent D. magna populations. The present study provides evidence for relative stability of genotypes in lake populations when compared to permanent pond populations. Jacobs (1982), however, reports larger shifts in genotypic frequencies from summer to winter in $D$. cucullata and $D$. hyalina (another lake species). Study of more populations is needed before a general statement can be made about patterns of genotypic fluctuations in lakes.
Many studies of permanent Daphnia populations have revealed significant deviations from Hardy-Weinberg proportions mostly due to heterozygote excesses (Hebert, 1983). Hebert (1983) has suggested that such findings signify heterosis and should be expected in permanent populations where prolonged parthenogenesis allows the time for culling of genotypes by natural selection. In the present study, the D. galeata mendotae population exhibited no deviations from Hardy-Weinberg proportions at two loci on any single sampling date; only after pooling all samples was there evidence for heterozygote excess at the GOT-locus. The D. cucullata population exhibited, at various times, Hardy-Weinberg deviations at both PGI and PGM. At the PGM locus, deviations were due to homozygote excesses. At the PGI locus, homozygote excesses were more common than heterozygote excesses but both types were observed. Thus, in the present study, there is a lack of compelling evidence for the heterosis thought to be operating in pond populations (Hebert, 1983), although more populations must be examined before general statements can be made.

Experimental manipulation of natural populations indicates that $D$. galeata mendotae genotypes respond differently to strong environmental perturbations (Mort and Jacobs, 1981). The present study, however, suggests a stable genotypic assemblage with only weak selection acting among clones under natural levels of environmental change. If lake clones are responding differently to environmental changes, then the effect may be slight shifts in clonal abundances rather than the clonal replacement seen in pond populations (Lynch, 1983). The results of the present study seem more consistent with Lynch's hypothesis (1983) that permanent populations should consist of generalist genotypes selected for similar phenotypic responses to a seasonal environment. The regularity of the phenotypic cycles exhibited by lake populations may be an indication that different genotypes have been selected for similarity in average phenotypic responses.

\footnotetext{
Acknowledgements We thank Jürgen Jacobs and an anonymous reviewer for valuable comments on earlier drafts of this paper, Eva Geißler for technical assistance, and Winfried Lampert and the members of the Abteilung Ökophysiologie for general support and assistance. A portion of the data is contained in a Ph.D. thesis submitted by M.A.M. to Dartmouth College. Financial support was provided by Dartmouth College, Sigma-Xi, and the Max-Planck-Gesellschaft.
} 


\section{REFERENCES}

BERGER, E. ANI) SUTHERLANI), J. 1978. Allozyme variation in two natural populations of Daphnia pulex. Heredity, 41, 13-23.

CHELIAK, W. M., MORGAN, K., STROBECK, C., YEH, F. C. H., AND DANCIK, B. P. 1983. Estimation of mating system parameters in plant populations using the EM algorithm. Theor. Appl. Genet., 65, 157-161.

HEBERT, P. D. N. 1974a. Enzyme variability in natural populations of Daphnia magna. I. Population structure in East Anglia. Evolution, 28, 546-556.

HEBFRT, P. D. N. 1974b. Enzyme variability in natural populations of Daphnia magna. II. Genotypic frequencies in permanent populations. Genetics, 77, 323-334.

HEBERT, P. I). N. 1974c. Enzyme variability in natural populations of Daphnia magna. III. Genotypic frequencies in intermittent populations. Genetics, 77, 335-341.

HFRFRT, P. D. N. 1974d. Ecological differences between genotypes in a natural population of Daphnia magna, Heredity, 33, 327-337.

HEBERT, P. D. N. 1980. The genetics of Cladocera. In Kerfoot, W. C. (ed.) Evolution and Ecology of Zooplankton Communities, University Press of New England, Hanover, New Hampshire.

HFBERT, P. D. N. 1983. Clonal diversity in cladoceran populations. In King, C. E. and Dawson, P. S. (eds.) Population Biology: Retrospect and Prospect, Columbia University Press, New York.

HEBERT, P. D. N. 1984. Demographic implications of genetic variation in zooplankton populations. In Wöhrmann, $\mathrm{K}$. and Loeschcke, V. (eds.) Population Biology and Evolution, Springer-Verlag, Berlin.

HEBERT, P. D. N. AND CREASE, T. J. 1980. Clonal coexistence in Daphnia pulex (Leydig): another planktonic paradox. Science, 207, 1363-1365.

HEBERT, P. D. N. AND MORAN, C. 1980. Enzyme variability in natural populations of Daphnia carinata. Heredity, 45, 313321.

HEBI:RT, P. D. N. AND WARD, R. D. 1972. Inheritance during parthenogensis in Daphnia magna. Genetics, 71, 639-642.

HEBER', P. D. N. ANI) WARD, R. I). 1976. Enzyme variability in natural populations of Daphnia magna. IV. Ecological differentiation and frequency changes of genotypes at Audley End. Heredity, 36, 331-341.
HERZIG, A. 1984. Resting eggs-ma source of continuous recruitment for pelagic populations? Verh. Internat. Verin. Limnol., 22, (in press).

HUTCHINSON, G. E. 1967. A treatise on limnology, Vol. II, John Wiley and Sons, New York.

JACOBS, J. 1982. Short-term and small-scale genetic differentiation in two partially parthenogenetic pelagic species of Daphnia. A preliminary report. In Jayakar, S. D. and Zonta, L. (eds.) Evolution and the Genetics of Populations, Proceedings of the Population Genetics Workshop, Pavia, September 1982, University of Pavia.

LEWONTIN, R. C. 1974. The genetic basis of evolutionary change. Columbia University Press, New York.

LYNCH, M. 1983. Ecological genetics of Daphnia pulex. Evolution, 37, 358-374.

LYNCH, M. 1984a. The genetic structure of a cyclical parthenogen. Evolution, 38, 186-203.

LYNCH, M. 1984b. The limits to selection in Daphnia. Evolution, $38,465-482$.

MANNING, J., KERFOOT, W. C. AND BERGER, E. M. 1978. Phenotypes and genotypes in cladoceran populations. Evolution, 32, 365-374.

MORT, M. A. 1983. E'slutionary implications of phenotypic and genetic variation in cladoceran populations. Ph. D. thesis, Dartmouth College, Hanover, New Hampshire.

MORT, M. A. ANI JACOBS, J. 1981. Differences among genotypic frequencies of undisturbed and manipulated populations of Daphnia. Oecologia, 50, 184-186.

SHAW, (. R. ANI) PRASAD, R. 1970. Starch gel electrophoresis of enzymes-a compilation of recipes. Biochemical Genetics, 4, 297-320.

WOLF, H. G. 1982. A comparison of different electrophoretic techniques for the detection of isoenzymes in single daphnids. Arch Hydrobiol., 95, 521-531.

wOLF, H. G. 1984. Population genetic investigations on Daphnia cucullata in the Schöhsee at Plön. Verh. Internat. Verein. Limnol., 22, (in press).

YOUNG, J. P. W. 1979a. Enzyme polymorphism and cyclic parthenogenesis in Daphnia magna. 1. Selection and clonal diversity. Genetics, 92, 953-970.

YOUNG, J. P. W. 1979b. Enzyme polymorphism and cyclic parthenogenesis in Daphnia magna. II. Heterosis following sexual reproduction. Genetics, 92, 971-982. 